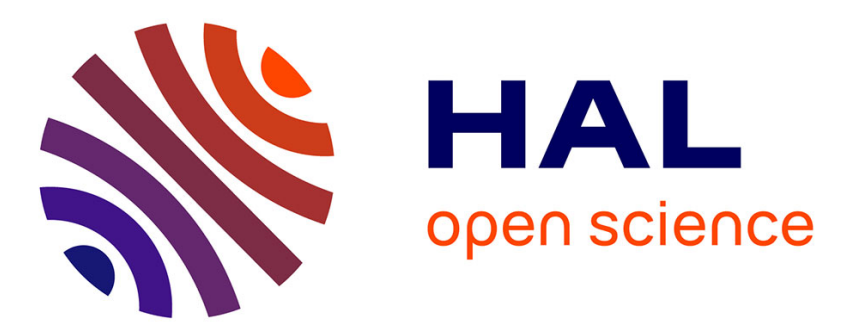

\title{
On the Flexibility of the Structural Framework of Cubic LAMOX Compounds, in Relationship with Their Anionic Conduction Properties
}

\author{
P. Lacorre, Ania Selmi, Gwenaël Corbel, Brigitte Boulard
}

\section{- To cite this version:}

P. Lacorre, Ania Selmi, Gwenaël Corbel, Brigitte Boulard. On the Flexibility of the Structural Framework of Cubic LAMOX Compounds, in Relationship with Their Anionic Conduction Properties. Inorganic Chemistry, 2006, 45 (2), pp.627-635. 10.1021/ic0513080 . hal-02134999

HAL Id: hal-02134999

https://hal-univ-lemans.archives-ouvertes.fr/hal-02134999

Submitted on 23 Jul 2019

HAL is a multi-disciplinary open access archive for the deposit and dissemination of scientific research documents, whether they are published or not. The documents may come from teaching and research institutions in France or abroad, or from public or private research centers.
L'archive ouverte pluridisciplinaire HAL, est destinée au dépôt et à la diffusion de documents scientifiques de niveau recherche, publiés ou non, émanant des établissements d'enseignement et de recherche français ou étrangers, des laboratoires publics ou privés. 


\title{
On the flexibility of the structural framework of cubic LAMOX compounds, in relationship with their anionic conduction properties
}

\author{
Philippe Lacorre*, Ania Selmi, Gwenaël Corbel, and Brigitte Boulard \\ Laboratoire des Oxydes et Fluorures, UMR CNRS 6010, Université du Maine \\ Avenue Olivier Messiaen, 72085 Le Mans cedex 9, France
}

\begin{abstract}
A mathematical analysis of the cubic crystal structure of fast oxide-ion conductor $\beta-\mathrm{La}_{2} \mathrm{Mo}_{2} \mathrm{O}_{9}$ (and derived members of the LAMOX family) shows that its cationic sublattice can behave as a semi-rigid framework. Tilt/rotation of rigid $\left[\mathrm{O}_{1} \mathrm{La}_{3} \mathrm{Mo}\right]$ anti-tetrahedral units about their 3 -fold axis can open up tunnels in the cationic framework, therefore favoring the mobility of $\mathrm{O} 2$ and $\mathrm{O} 3$ oxide ions located in these tunnels, as confirmed by molecular dynamics simulations. Such a process is likely to assist the anionic transport and explain the postulated transition from Arrhenius-type to VTF(Vogel-Tammann-Fulcher)-type behavior propounded to account for the peculiar conductivity curvature observed at high temperature in all the cubic LAMOX compounds. It also clarifies the correlated extra cell volume expansion observed at the same temperature in all these materials.
\end{abstract}

\section{Introduction}

Many ionic conductors are known to exhibit an orderdisorder-type phase transition toward a highly conducting high-temperature phase. It is the case $^{1}$ of fast oxide-ion conductor $\mathrm{La}_{2} \mathrm{Mo}_{2} \mathrm{O}_{9}$ whose conductivity above the $\alpha / \beta$ phase transition $\left(\right.$ at $580{ }^{\circ} \mathrm{C}$ ) is about 5 times larger than that of yttrium-stabilized zirconia YSZ8\%. Most cationic substitutions, leading to the so-called LAMOX family, ${ }^{2}$ stabilize at room temperature the cubic $\beta$ phase. The conductivity curves of these cubic phases exhibit the conventional Arrheniustype behavior at low temperature, but deviate from it at higher temperature (generally above ca. $400{ }^{\circ} \mathrm{C}$ ), with first an increase and then a leveling off of conductivity. Such an increase, which cannot originate from an increase of the carrier concentration alone, ${ }^{3}$ has been interpreted as resulting from a transition toward a high-temperature VogelTamman-Fulcher (VTF) regime. ${ }^{4}$

Arrhenius and VTF models are prototypes for activated and assisted transport mechanisms, respectively. The former

* To whom correspondence should be addressed. E-mail: philippe.lacorre@univ-lemans.fr.

(1) Lacorre, P.; Goutenoire, F.; Bohnké, O.; Retoux, R.; Laligant, Y. Nature 2000, 404, 856-858.

(2) Goutenoire, F.; Isnard, O.; Suard, E.; Bohnké, O.; Laligant, Y.; Retoux R.; Lacorre, P. J. Mater. Chem. 2001, 11, 119-124.

(3) Georges, S.; Bohnké, O.; Goutenoire, F.; Laligant, Y.; Fouletier, J.; Lacorre P. Submitted to Solid Statc Ionics.

(4) Georges, S.; Goutenoire, F.; Bohnké, O.; Steil, M. C.; Skinner, S. J.; Wiemhöfer, H.-D.; Lacorre, P. J. New. Mater. Electrochem. Syst. 2004, $7,51-57$
(Arrhenius) depicts thermally activated ionic motion in solids, whereas the latter (VTF) is used to model diffusion of highly mobile ionic species, whose migration is assisted by the motion (in polymers ${ }^{5}$ or salt-polymer complexes, above their glass transition) or libration (in ceramics ${ }^{6}$ ) of the counterionic matrix. In ceramics the semirigid structural framework, acting as a template for mobile ions, remains solid but its rigid constitutive parts are able to tilt and rotate with respect to each other, thus opening up migration pathways and favoring diffusion. Such a process has been advanced to explain the high-temperature ionic motion of LLTO lithium-ion conductors, where the octahedral tilting/rotation around perovskite cages is thought to favor lithium diffusion from cage to cage through the opening/closing of the intercage bottleneck. ${ }^{6}$ In salt-polymer complexes, the VTF regime is interpreted as originating from the natural thermal expansion, which, above a critical temperature $T_{0}$, results in an excess free volume redistributable without any enthalpic contribution. ${ }^{7}$ On another hand, when oxide glasses with ionic conducting properties are modified by the addition of metal-halide salts, it has been shown ${ }^{8}$ that the resulting increase in ionic conductivity scales perfectly (through a cubic power law)

(5) Ratner, M. A. In Polymer Electrode Reviews; MacCallum, J. R., Vincent, C. A., Eds.; Elsevier Applied Science: London, 1987; Vol. 1, pp 173-236.

(6) Bohnké, O.; Bohnké, C.; Fourquet, J.-L. Solid State Ionics 1996, 91, $21-31$.

(7) Souquet, J.-L.; Duclot, M.; Levy, M. Solid State Ionics 1996, 85, 149157.

(8) Swenson J.; Börjesson, L. Phys. Rev. Lett. 1996, 77, 3569-3572. 
with the volume expansion generated by the doping. Correlations between ionic conduction and thermal (or chemical) expansion are well-known in oxide ion conductors. Some alternative explanations to free volume have been advanced to explain them, such as the dependence of both conduction and expansion on oxygen vacancy concentration, or the decreasing interaction between ions when the crystal expands (see for instance refs 9 and 10 and references therein). Among the studies focusing more specifically on free volume, depending on the structural type, correlations with ionic conduction have either been clearly evidenced (fluorite $^{11}$ or brownmillerite ${ }^{12}$ types) or shown to be partly counterbalanced by conflicting effects (perovskite ${ }^{13,14}$ or brownmillerite ${ }^{15}$ types).

The purpose of this paper is to try to evidence such type of correlations between oxide-ion conduction and thermal expansion in the LAMOX family, and to interpret it in terms of the flexibility of its structural framework.

\section{Experimental Section}

Synthesis. Powder samples were prepared by conventional solidstate reaction of intimate mixtures of elementary oxides or carbonates. A preheating of several hours at $500{ }^{\circ} \mathrm{C}$ was applied for pre-reaction in order to avoid molybdenum oxide sublimation. One or several firings were performed at high temperature (generally between 900 and $1200{ }^{\circ} \mathrm{C}$ depending on composition, ${ }^{2,16}$ with intermediate grindings) until a pure phase is obtained. Pellets with high relative density $(>95 \%)$ were obtained from ball-milled powders (FRITSCH planetary micromill pulverizette apparatus, with $900 \mathrm{mg}$ of sample in agate vials together with six $10 \mathrm{~mm}$ diameter agate balls, in ethanol; 4 alternations of 15 min milling sequences at $700 \mathrm{rpm}$, with a 15 min pause in between). After mixing with an organic bending agent, dried powders were first shaped in a uniaxial press ( $\sim 5 \mathrm{~mm}$ diameter and 3-5 mm thickness) and then pellets were isostatically pressed at $500 \mathrm{MPa}$ in a Top Industrie room-temperature apparatus. The optimal sintering conditions were determined by dilatometry (see below).

X-ray Diffraction. X-ray powder thermodiffractograms were recorded in air from $\mathrm{RT}$ to $1060{ }^{\circ} \mathrm{C}$ on a $\theta / \theta$ Bragg-Brentano

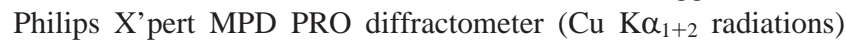
equipped with the X'celerator detector and an Anton Paar HTK1200 high-temperature heating chamber. Diffractograms were collected at each temperature for $184 \mathrm{~min}$ in the $\left[15-130^{\circ}\right]$ scattering angle range, with a $0.0167^{\circ}$ step (heating rate $10{ }^{\circ} \mathrm{C} / \mathrm{min}$ between each thermal step, with 20 min temperature stabilization before recording). Crystal cell parameters were determined by full pattern matching refinement of the powder XRD patterns in space group $P 2{ }_{1} 3$ using the Fullprof program. ${ }^{17}$

(9) Ullmann, H.; Trofimenko, N.; Tietz, F.; Stover, D.; Ahmad-Khanlou, A. Solid State Ionics 2000, 138, 79-90.

(10) Kharton, V. V.; Yaremchenko, A. A.; Patrakeev, M. V.; Naumovich, E. N.; Marques F. M. B. J. Eur. Ceram. Soc. 2003, 23, 1417-1426.

(11) Yamamura, H.; Matsui, K.; Kakinuma, K.; Mori, T. Solid State Ionics 1999, 123, 279-285.

(12) Kakinuma, K.; Yamamura, H.; Haneda, H.; Atake, T. Solid State Ionics 2002, 154-155, 571-576.

(13) Nomura, K.; Tanase, S. Solid State Ionics 1997, 98, 229-236.

(14) Ma, G.; Shimura, T.; Iwahara, H. Solid State Ionics 1999, 120, 5160 .

(15) Kakinuma, K.; Takahashi, N.; Yamamura, H.; Nomura, K.; Atake, T. Solid State Ionics 2004, 168, 69-74.

(16) Corbel, G.; Laligant, Y.; Goutenoire, F.; Suard, E.; Lacorre, P. Chem. Mater. 2005, 17, 4678-4684.

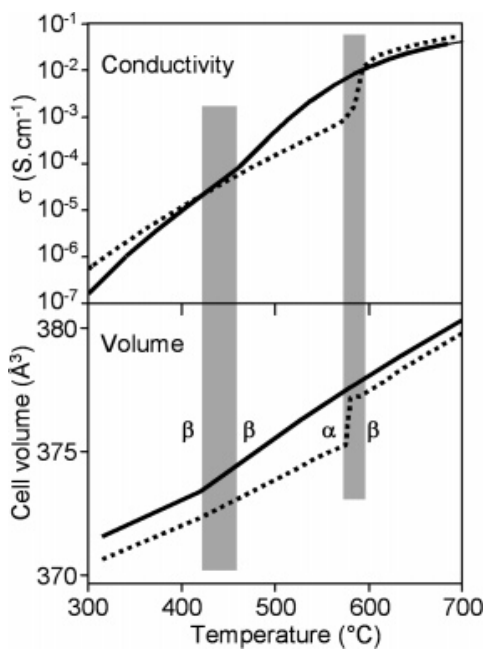

Figure 1. Comparison between measured conductivity increase (top) and measured volumic expansion (bottom) as a function of temperature for $\mathrm{La}_{2}-$ $\mathrm{Mo}_{2} \mathrm{O}_{9}$ (dotted lines) and $\mathrm{La}_{1.9} \mathrm{Sr}_{0.1} \mathrm{Mo}_{2} \mathrm{O}_{8.95}$ (full lines). The gray vertical bars indicate the monoclinic/cubic $\alpha / \beta$ phase transition in $\mathrm{La}_{2} \mathrm{Mo}_{2} \mathrm{O}_{9}$ at high temperature and the postulated Arrhenius/VTF transition in cubic $\mathrm{La}_{1.9}{ }^{-}$ $\mathrm{Sr}_{0.1} \mathrm{Mo}_{2} \mathrm{O}_{8.95}$ at lower temperature.

Dilatometry. For dilatometric measurements, a vertical SETARAM TMA Setsys Evolution 16 dilatometer was used. Linear thermal expansion coefficients were measured on sintered pellets in a $20 \mathrm{~mL} / \mathrm{min}$ air flow from $\mathrm{RT}$ to $1000{ }^{\circ} \mathrm{C}\left(5^{\circ} \mathrm{C} / \mathrm{min}\right.$ heating rate).

Conductivity Measurements. Complex impedance measurements were performed on dense pellets, with thin platinum films (deposited by magnetron sputtering on both flat faces) as electrodes. The impedance spectra were recorded over the $32 \mathrm{MHz}$ to $0.1 \mathrm{~Hz}$ frequency range (signal amplitude $50 \mathrm{mV}$ ) in dry air flow at high temperature using a Solartron SI 1260 frequency response analyzer combined with the Dielectric Interface (Solartron 1296). A $35 \mathrm{~min}$ thermalization time was applied before each measurement.

Molecular Dynamics. A series of molecular dynamics (MD) simulations were performed in order to test the effect of antitetrahedra rotation on oxygen mobility. The pair-potential $U_{i j}$ used in this study was the Busing approximation of Born-MayerHuggins form

$$
U\left(r_{i j}\right)=\frac{z_{i} z_{j}}{r_{i j}}+f_{\mathrm{o}}\left(b_{i}+b_{j}\right) \exp \left(\frac{a_{i}+a_{j}-r}{b_{i}+b_{j}}\right)-\frac{c_{i} c_{j}}{r^{6}}
$$

where $r_{i j}$ is the distance between ions, $z_{i}$ the effective valence of ion $i, f_{\mathrm{o}}$ a constant equal to $6.947 \times 10^{-19} \mathrm{~J} \AA^{-1}, c_{i}$ and $c_{j}$ the parameters of the molecular force term, and $a_{i}$ and $b_{i}$ the repulsion term parameters. A list of the parameters used for the current simulation can be found in Table 1 .

\section{Conductivity and Crystal Cell Volume Anomalies in the LAMOX Family}

A correlation between conductivity increase and volume expansion obviously exists in $\mathrm{La}_{2} \mathrm{Mo}_{2} \mathrm{O}_{9}$ (see Figure 1, experimental data) since the $\alpha / \beta$ phase transition is accompanied by both an increase of anionic conductivity of about 1 order of magnitude ${ }^{1}$ and a cell volume expansion of ca. $0.5 \% .{ }^{18}$ In the cubic members of the LAMOX family, of course no such abrupt change in cell volume is observed

(17) Rodriguez-Carvajal, R. J. Phys.: Condens. Matter 1993, 192, 5569. 
since no symmetry change occurs in the whole temperature range. However, a change in the thermal expansion coefficient of several cubic members of the LAMOX family (namely, $\mathrm{V}-, \mathrm{W}-$, and Bi-substituted compounds) above ca. $650 \mathrm{~K}$ has already been observed. ${ }^{19}$ It was associated by the authors to either a disordering of oxygen sublattice or possibly a minor oxygen loss indicated by increasing of n-type electron transference number when the temperature increases. We think the second alternative is most unlikely, specially in the case of $\mathrm{W}$-substituted compounds which are known to be more stable to reducibility than $\mathrm{La}_{2} \mathrm{Mo}_{2} \mathrm{O}_{9},{ }^{20}$ this last compound having a very low electronic transference number at $750{ }^{\circ} \mathrm{C}$ in air (around $10^{-3}$, from ref 4). Our interpretation is that such a change in volume expansion should rather be correlated with a change in oxygen transport mechanism from thermally activated (Arrhenius) at low $T$ to thermally assisted (VTF) at high $T$, in other words with a transition from a static to a dynamic disorder of oxide ions. As a matter of fact, such an increase in cell volume occurs at the same temperature as the conductivity increase (which can also be seen in oxygen tracer diffusion measurements ${ }^{21}$ ). This is illustrated in Figure 1 with the experimental conductivity and volumetric curves of another cubic member of the LAMOX family, $\mathrm{La}_{1.9} \mathrm{Sr}_{0.1} \mathrm{Mo}_{2} \mathrm{O}_{8.95}$.

The previous assumption is in qualitative agreement with the correlation established in the earlier study on modified oxide glasses. ${ }^{8}$ The advantage of a crystalline over an amorphous matrix is that the known crystal host framework can be directly analyzed in terms of the ability of its atomic arrangement to accommodate for such an extra volume expansion relative to its own natural thermal expansion. The next section is devoted to such an analysis.

\section{Flexibility of the $\beta$ - $\mathrm{La}_{2} \mathrm{Mo}_{2} \mathrm{O}_{9}$ Cationic Framework}

Defining the Most Appropriate Reference Frame. The conventional manner to represent an oxide structure, featuring the ligand coordination environment of cations, is not the most appropriate way to describe the structural arrangement of $\beta-\mathrm{La}_{2} \mathrm{Mo}_{2} \mathrm{O}_{9}$. This is due to the fact that the partial occupancy of most oxide ions sites does not allow an easy or convenient polyhedral representation, especially when our understanding of transport properties requests a differentiation between those oxide ions which are likely to migrate and those which belong to the host framework.

Recently, we have proposed a new kind of description of the $\beta-\mathrm{La}_{2} \mathrm{Mo}_{2} \mathrm{O}_{9}$ structural arrangement based on antipolyhedra. ${ }^{16}$ As a matter of fact, fully occupied sites in the

(18) (a) Lacorre, P.; Goutenoire, F.; Altorfer, F.; Sheptyakov, D.; Fauth, F.; Suard, E. In Advances in Science and Technology 33, 10th International Ceramics Congress; Vincenzini, P., Ed.; Techna Srl: Florence, Italy, 2003; Part D, pp 737-747. (b) Georges, S.; Goutenoire, F.; Altorfer, F.; Sheptyakov, D.; Fauth, F.; Suard, E.; Lacorre, P. Solid State Ionics 2003, 161, 231-241.

(19) (a) Marozau, I. P.; Marrero-López, D.; Shaula, A. L.; Kharton, V. V.; Tsipis, E. V.; Núñez, P.; Frade, J. R. Electrochim. Acta 2004, 49, 3517-3524. (b) Marozau, I. P.; Shaula, A. L.; Kharton, V. V.; Vyshatko, N. P.; Viskup, A. P.; Frade, J. R.; Marques F. M. B. Mater. Res. Bull. 2005, 40, 361-371.

(20) Georges, S.; Goutenoire, F.; Laligant, Y.; Lacorre, P. J. Mater. Chem. 2003, 13, 2317-2321.

(21) Georges, S.; Skinner, S. J.; Steil, M. C.; Lacorre, P. J. Chem. Soc., Dalton Trans. 2004, 19, 3101-3105.

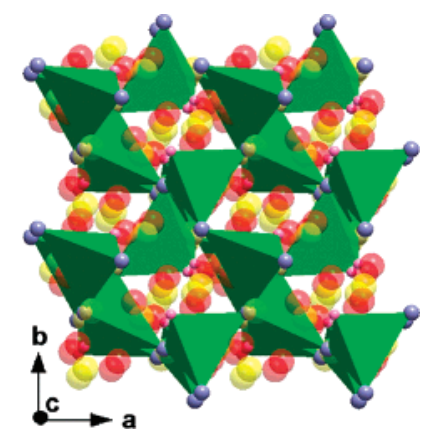

Figure 2. Representation of the $\beta-\mathrm{La}_{2} \mathrm{Mo}_{2} \mathrm{O}_{9}$ structural type in terms of a [OLaMo] framework built up from La corner-sharing [O1 $\mathrm{La}_{3} \mathrm{Mo}$ ] antitetrahedral units (green), with $\mathrm{O} 2$ and $\mathrm{O} 3$ oxide ions sites imbedded in its tunnels. ${ }^{16}$ Pink spheres $=\mathrm{Mo}^{6+}$ or substitute, blue spheres $=\mathrm{La}^{3+}$ or substitute, yellow and red transparent spheres $=\mathrm{O} 2$ and $\mathrm{O} 3$ oxide ion sites, respectively.

structure (La, Mo, and O1, in 4a positions of space group $P 2_{1} 3$ ) form tetrahedral units around the $\mathrm{O} 1$ sites, hereafter called $\left[\mathrm{O} 1 \mathrm{La}_{3} \mathrm{Mo}\right]$ anti-tetrahedra. These anti-tetrahedral units are supposed to be the most stable part of the structure and O1 the less mobile oxide ion since it is surrounded by four cations. In comparison, $\mathrm{O} 2$ and $\mathrm{O} 3$ are surrounded by three cations only ${ }^{22}$ and are therefore less trapped than $\mathrm{O} 1$. Moreover, $\mathrm{O} 2$ and $\mathrm{O} 3$ sites are partially occupied and have larger and more anisotropic Debye-Waller thermal factor than $\mathrm{O} 1 .{ }^{18}$ Each $\left[\mathrm{O} 1 \mathrm{La}_{3} \mathrm{Mo}\right]$ anti-tetrahedron shares its three La vertexes with two other anti-tetrahedra to form a 3D framework with formulation [OLaMo]. Such a framework delineates tunnels in which are located partially occupied $\mathrm{O} 2$ and $\mathrm{O} 3$ sites on $12 \mathrm{~b}$ positions (see Figure 2). Incidentally, these two $\mathrm{O} 2$ and $\mathrm{O} 3$ sites are thought to be occupied by charge carriers, ${ }^{21}$ thus providing an interesting and suggestive connection with transport properties. In this new description, the molybdate formula becomes $\left[\mathrm{OLaMo}_{2} \mathrm{O}_{7} \square\right.$ with seven oxide ions (and a vacancy, according to the LPS concept ${ }^{23}$ ) inside the voids of the [OLaMo] framework.

We thus adopt, with this kind of representation, a symmetrical approach ${ }^{24}$ to that commonly used in describing the structure/properties relationships in cation conductors: indeed, cationic anti-polyhedra for anionic conductors are equivalent to (or play the same role as) anionic polyhedra for cationic conductors. For instance, migrating oxide anions are likely to move, inside the $\left[\mathrm{OLa}_{3} \mathrm{Mo}\right]$ anti-tetrahedra-based framework in $\beta-\mathrm{La}_{2} \mathrm{Mo}_{2} \mathrm{O}_{9}$, the same way as lithium cations do inside the $\left[\mathrm{TiO}_{6}\right]$ octahedral-based framework in the LLTO perovskite structure.

Therefore, what we want to check now is whether antitetrahedra in cubic LAMOX can easily tilt and rotate the same way as octahedra can do in the perovskite structure.

Anti-tetrahedral [O1LaMo] Host Matrix as a Semirigid Framework. As reported in the Introduction, lithium migration above room temperature in LLTO perovskites is thought to be assisted from perovskite cage to perovskite cage by octahedra tilting/rotation. In this respect the octahedral framework is considered to be semirigid, with

(22) Emery, J.; Massiot, D.; Lacorre, P.; Laligant, Y.; Conder, K. Magn. Reson. Chem. 2005, 43, 366-371.

(23) Lacorre, P. Solid State Sci. 2000, 2, 755-758.

(24) O'Keeffe M.; Hyde, B. G. Struct. Bonding 1985, 61, 77-144. 
rigid octahedral units allowed to rotate around their vertexes. The equivalent of the perovskite rigid octahedral unit in cubic LAMOX is the anti-tetrahedral [OLa $\left.{ }_{3} \mathrm{Mo}\right]$ unit represented in Figure 3, whose geometry in this symmetry is fixed by the three interatomic distances La-La $\left(d_{11}\right)$, La-Mo $\left(d_{1 \mathrm{~m}}\right)$, and Mo-O $1\left(d_{\mathrm{mo}}\right)$. In space group $P 2_{1} 3$, all three atoms are located in 4a sites on a 3-fold axis (O1 and Mo on the same 3 -fold axis), with only one atomic coordinate each $(x=y=$ $z$ ). Indeed the interatomic distances can be expressed in terms of the atomic positions (hereafter called $x_{1}, x_{\mathrm{m}}$, and $x_{\mathrm{o}}$ for $\mathrm{La}$, Mo, and O1, respectively) and of the $a$ cubic cell parameter. The main idea is then to deduce from these relationships the expression of the atomic position parameters $x_{1}, x_{\mathrm{m}}$, and $x_{\mathrm{o}}$ as a function of the cell parameter $a$ and of geometrical characteristics of the anti-tetrahedra $d_{\mathrm{ll}}, d_{\mathrm{lm}}$, and

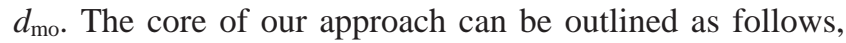
with $f(), f^{\prime}(), f^{\prime \prime}(), g^{\prime}(), g^{\prime \prime}(), h^{\prime \prime}()$, etc..., representing functions of () :

$$
\begin{gathered}
d_{11}=g^{\prime}\left(a, x_{1}\right) \Longrightarrow x_{1}=f^{\prime}\left(a, d_{11}\right) \\
d_{1 \mathrm{~m}}=g^{\prime \prime}\left(a, x_{1}, x_{\mathrm{m}}\right) \Longrightarrow x_{\mathrm{m}}=h^{\prime \prime}\left(a, x_{1}, d_{\mathrm{lm}}\right)=f^{\prime \prime}\left(a, d_{11}, d_{1 \mathrm{~m}}\right) \\
d_{\mathrm{mo}}=g^{\prime \prime \prime}\left(a, x_{\mathrm{m}}, x_{\mathrm{o}}\right) \Longrightarrow x_{\mathrm{o}}=h^{\prime \prime \prime}\left(a, x_{\mathrm{m}}, d_{\mathrm{mo}}\right)=f^{\prime \prime}\left(a, d_{11}, d_{1 \mathrm{l}}, d_{\mathrm{mo}}\right)
\end{gathered}
$$

leading finally to

$$
\left(x_{1}, x_{\mathrm{m}}, x_{\mathrm{o}}\right)=f\left(a, d_{11}, d_{1 \mathrm{~m}}, d_{\mathrm{mo}}\right)
$$

The expressions of $d_{\mathrm{ll}}, d_{\mathrm{lm}}$, and $d_{\mathrm{mo}}$ are quadratic forms of $x_{1}, x_{\mathrm{m}}$, and $x_{\mathrm{o}}$. The atomic coordinates are therefore roots of the corresponding equations that can be successively inserted into the next equation in order to get a global solution to the system, provided that these roots exist in the functional definition ranges (positive discriminant). One ends up with the following set of expressions:

$$
x_{1}=\left(7-\sqrt{ } \Delta_{1}\right) / 8
$$

with

$$
\begin{gathered}
\Delta_{1}=8\left(d_{11} / a\right)^{2}-3 \\
x_{\mathrm{m}}=\left(2-\sqrt{ } \Delta_{2}-x_{1}\right) / 3
\end{gathered}
$$

with

$$
\begin{gathered}
\Delta_{2}=-8 x_{1}^{2}+14 x_{1}+3\left(d_{1 \mathrm{~m}} / a\right)^{2}-13 / 2 \\
x_{\mathrm{o}}=x_{\mathrm{m}}+d_{\mathrm{mo}} /(a \sqrt{ } 3)
\end{gathered}
$$

Formula ( $\left.1^{\prime}\right)$ is valid, and therefore the cationic arrangement is self-consistent, only if $\Delta_{1} \geq 0$, that is, from ( $\left.1^{\prime \prime}\right)$ : $d_{11} / a \geq \sqrt{ }[3 / 8] \cong 0.61237$. According to $\left(1^{\prime}\right)$, the maximum possible value of $x_{1}$ is obtained for $\Delta_{1}=0$, that is, $x_{1}^{\max }=$ $7 / 8=0.875$.

Formula $\left(2^{\prime}\right)$ is more complex since it relates the atomic positions of two different atoms. Of course, it requests that $\Delta_{2} \geq 0$ which, through ( $\left.2^{\prime \prime}\right)$, delimits bounds on interatomic distances and/or lanthanum position. Defining precisely these

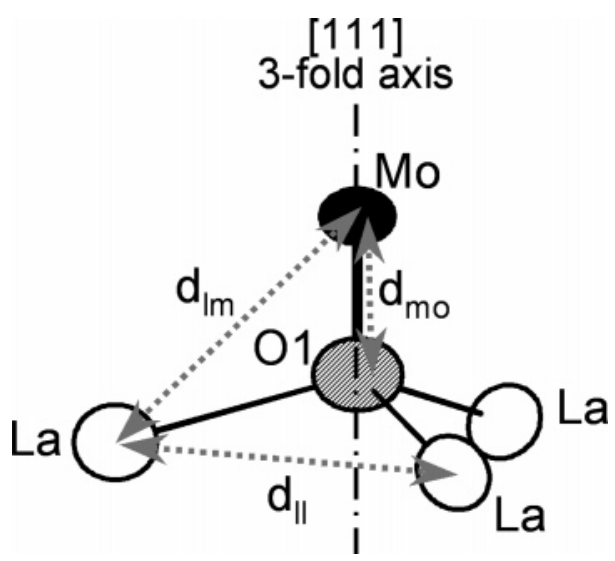

Figure 3. $\left[\mathrm{O} 1 \mathrm{La}_{3} \mathrm{Mo}\right]$ anti-tetrahedral basic units, with the interatomic distances considered in the text.

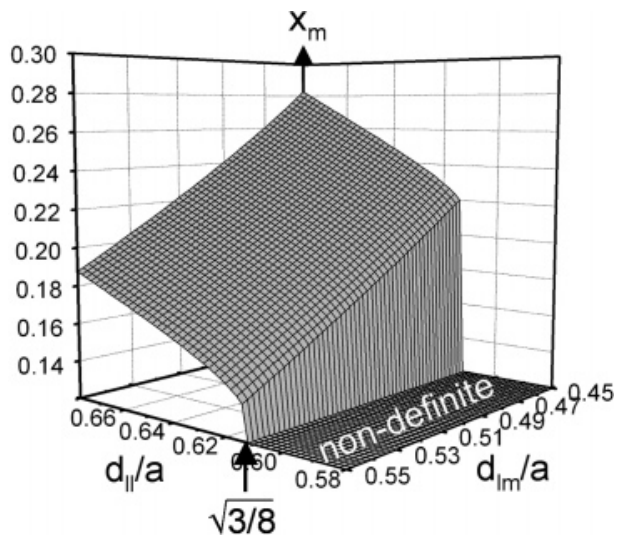

Figure 4. Molybdenum atomic coordinate $x_{\mathrm{m}}$ as a function of $d_{\mathrm{l}} / a$ and $d_{\operatorname{lm}} / a$ in a semirigid [OLaMo] framework.

bounds is of little interest here. Just notice that, for the current study range of relevance (see below), $\Delta_{2}$ is always positive definite. An illustration is given in Figure 4, which shows the evolution of $x_{\mathrm{m}}$ as a function of $d_{11} / a$ and $d_{\mathrm{lm}} / a$ (when either the geometry of anti-tetrahedral units or the cell parameter are modified).

Finally, formula ( $\left.3^{\prime}\right)$ is a straightforward relationship which relates the $\mathrm{O} 1$ site position to the Mo site position through their interatomic distance.

The interesting point about the current analysis is that, given a reasonable set of $\mathrm{La}-\mathrm{La}, \mathrm{La}-\mathrm{Mo}$, and $\mathrm{Mo}-\mathrm{O} 1$ interatomic distances and a cubic cell parameter, it is possible to find the La, Mo, and $\mathrm{O} 1$ atomic positions which satisfy this set of distances. In other words, given the geometry of a rigid $\left[\mathrm{O} 1 \mathrm{La}_{3} \mathrm{Mo}\right.$ ] anti-tetrahedral unit, it is possible, for any value of the $a$ cubic cell parameter (smaller than $\left.d_{11} / \sqrt{ }[3 / 8]\right)$, to find the atomic coordinates which satisfy the anti-tetrahedra geometry (see Figure 5). This is an important result since it shows that the LAMOX anti-framework can be, at least theoretically, flexible enough to accommodate, without any change in symmetry (the above calculations being carried out in the $P 2{ }_{1} 3$ space group), the tilt/rotation of rigid anti-tetrahedral units and concomitant cell volume change. The anti-framework can thus be folded or unfolded by just closing or opening up the $\mathrm{O} 1-\mathrm{La}-\mathrm{O} 1$ interunits angle without modifying the geometry of the anti-tetrahedral units. 


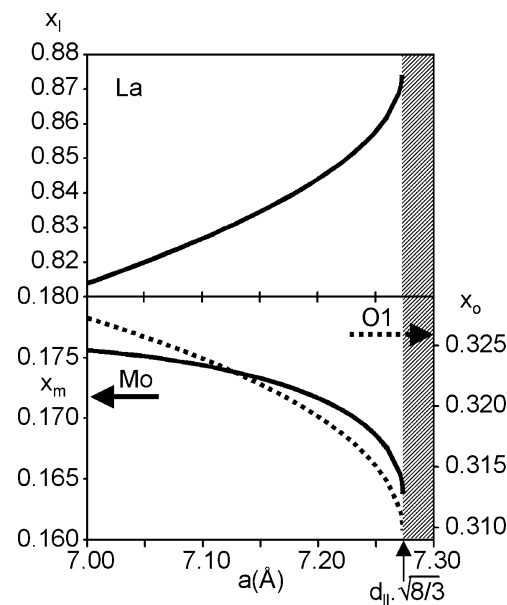

Figure 5. Position of the atoms of rigid $\left[\mathrm{O} 1 \mathrm{La}_{3} \mathrm{Mo}\right]$ anti-tetrahedral units in the crystal cell as a function of the cubic cell parameter (from interatomic distances measured in $\beta-\mathrm{La}_{2} \mathrm{Mo}_{2} \mathrm{O}_{9}$ at $670{ }^{\circ} \mathrm{C}: 1^{18} d_{1 \mathrm{ll}}=4.454 \AA, d_{\mathrm{lm}}=3.703$ $\AA, d_{\mathrm{mo}}=1.839 \AA$ ).

Figure 6 shows, from two different standpoints, the unfolding process. Along the tunnels, one can clearly see that the anti-tetrahedra tilting opens up the channels, thus releasing extra free volume for mobile ions. The view along the 3 -fold axis (main diagonal axis of the cubic cell) is also interesting because it makes clear the true nature of the antitetrahedra movement during the folding/unfolding process: it consists of a rotation around the 3-fold axes ([111] directions) of the structure, passing through the [O1-Mo] axis of the anti-tetrahedra units. The rotation angle $\delta$ can be calculated from the $(x, y)$ La atomic coordinates in a hexagonal reference frame, obtained by applying the rhombohedral-to-hexagonal transformation matrix to the $\mathrm{La}$ coordinates in cubic reference (see ref 25). It gives a simple relationship between $\delta$ and $x_{1}$ or $d_{11} / a$ :

$$
\begin{aligned}
\tan (\delta) & =\left(8 x_{1}-7\right) / \sqrt{ } 3 \\
& =-\sqrt{ }\left[8\left(d_{11} / a\right)^{2} / 3-1\right]
\end{aligned}
$$

or $a$ as a function of $\delta$ :

$$
a=d_{11} / \sqrt{ }\left[3\left(1+\tan ^{2}(\delta)\right) / 8\right]
$$

In these formulas $\delta$ is negative, $\delta=0$ corresponding to maximal volume expansion (for $x_{1}=7 / 8$ or $d_{11} / a=\sqrt{ }[3 / 8]$ ). Figure 7 shows the calculated cell parameter evolution when the rotation angle varies, as deduced from formula (6).

4.3. Framework Flexibility and Ionic Conductivity. In an ionic conductor, the free volume is a volume available for ions to move. The larger this volume, the higher the ionic mobility. In the hypothesis of an Arrhenius/VTF type

(25) Hahn, Th., Ed. International Tables for Crystallography, Vol. A, SpaceGroup Symmetry, 4th ed.; Kluwer Academic Publishers: Norwell, MA, 1995; p 78. Namely, the

$$
\left[\begin{array}{lll}
-1 / 3 & 2 / 3 & -1 / 3 \\
-2 / 3 & 1 / 3 & 1 / 3 \\
1 / 3 & 1 / 3 & 1 / 3
\end{array}\right]
$$

matrix is applied to the $\left(-1 / 2+x_{1}, 3 / 2-x_{1}, 1-x_{1}\right)$ lanthanum coordinates.
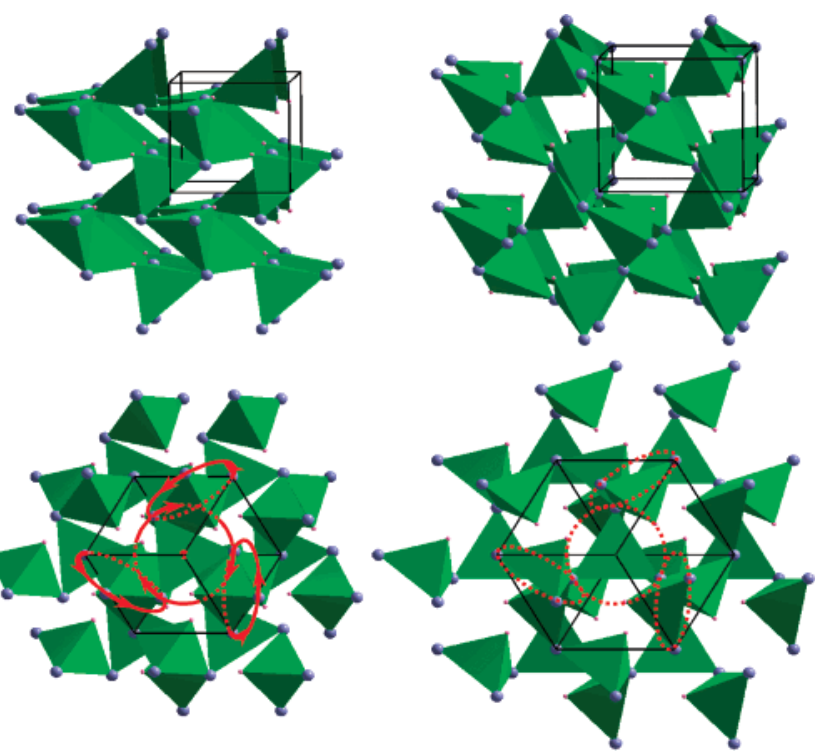

Figure 6. Folded (left, exaggerated) and unfolded (right) anti-framework as viewed along two directions of the $\beta-\mathrm{La}_{2} \mathrm{Mo}_{2} \mathrm{O}_{9}$ type structure: along the tunnels parallel to the cubic cell axis (upper) and along the 3 -fold axis (lower). The rotation of $\left[\mathrm{O} 1 \mathrm{La}_{3} \mathrm{Mo}\right]$ anti-tetrahedral units is outlined.

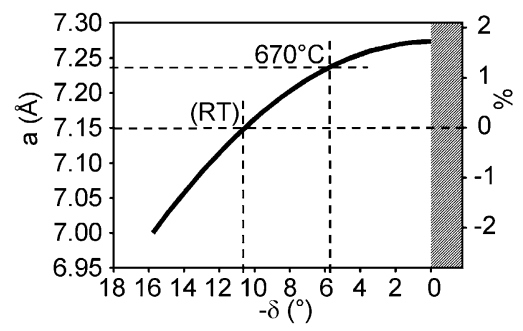

Figure 7. Calculated cubic cell parameter as a function of the $\delta$ rotation angle of rigid $\left[\mathrm{O}_{\mathrm{La}} \mathrm{Mo}\right]$ anti-tetrahedral units (with imposed geometry $d_{\mathrm{ll}}=4.454 \AA, d_{\mathrm{lm}}=3.703 \AA, d_{\mathrm{mo}}=1.839 \AA$ ). The dashed lines indicate the cell parameter and rotation angle of $\beta-\mathrm{La}_{2} \mathrm{Mo}_{2} \mathrm{O}_{9}$ at $670{ }^{\circ} \mathrm{C}$ (from crystal structure data, ref 18) and their approximation in a pseudo-cubic cell at room temperature.

transition, it seems reasonable to think that the increase of mobility in the VTF regime is correlated to an expansion of free volume, and therefore in our case of the crystal cell parameter. Such an expansion and its correlation with the conductivity increase are clearly evidenced in the experimental data displayed in Figure 1. It is also observed in all other cubic members of the LAMOX family (see Figure 8) with more or less magnitude depending on the substituent, which also influences the Arrhenius/VTF transition temperature. ${ }^{3}$ Two expansion regimes are observed: a regular one at low temperature, with constant expansion coefficient, and an extra expansion at higher temperature, correlated to the appearance of the VTF regime. From the very nature of the VTF mechanism, the host matrix is supposed to assist oxygen migration, and it is likely that the flexibility of the LAMOX framework is at the origin of the observed volume increase, through anti-tetrahedral rotation/vibration. The "empty" volume (cell volume - atomic volume) is relatively large in $\mathrm{La}_{2} \mathrm{Mo}_{2} \mathrm{O}_{9}$ since it represents about $38 \%$ of the cell volume (as compared to $26 \%$ in a close packed arrangement). Any additional volume freed up by the anti-tetrahedra rotation is likely to favor the ionic mobility, or to be correlated to it. Figure 9 reports the experimental thermal expansion of the 


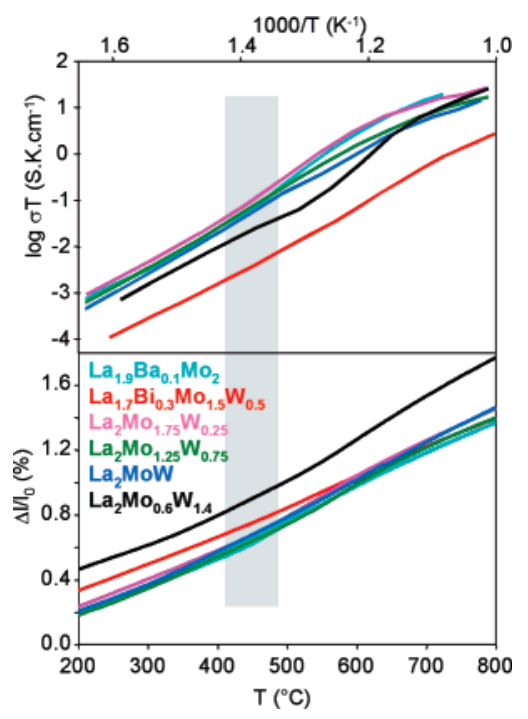

Figure 8. Departure from linearity at high temperature in the thermal expansion (bottom) and the Arrhenius plot of conductivity (top) of a series of LAMOX compounds (whose cationic stoichiometry is indicated). The two temperature scales coincide around $1000 / T(\mathrm{~K}) \sim 1.4, T \sim 440{ }^{\circ} \mathrm{C}$.

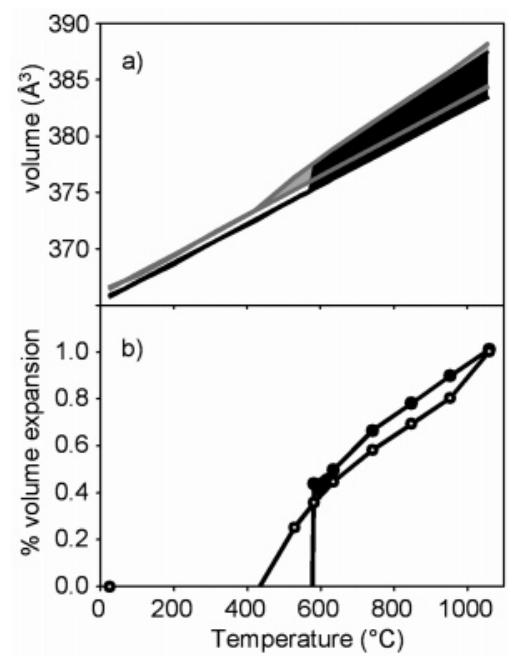

Figure 9. Experimental LAMOX cell volume expansion with temperature: (a) raw data with emphasis on extra expansion relative to regular thermal expansion $\left(\mathrm{La}_{2} \mathrm{Mo}_{2} \mathrm{O}_{9}\right.$ in black and $\mathrm{La}_{1.9} \mathrm{Sr}_{0.1} \mathrm{Mo}_{2} \mathrm{O}_{8.95}$ in gray); (b) relative extra volume expansion in excess to regular thermal expansion (black circles for $\mathrm{La}_{2} \mathrm{Mo}_{2} \mathrm{O}_{9}$, open circles for $\mathrm{La}_{1.9} \mathrm{Sr}_{0.1} \mathrm{Mo}_{2} \mathrm{O}_{8.95}$ ).

$\mathrm{La}_{2} \mathrm{Mo}_{2} \mathrm{O}_{9}$ and $\mathrm{La}_{1.9} \mathrm{Sr}_{0.1} \mathrm{Mo}_{2} \mathrm{O}_{8.95}$ cell volumes (a) and the same volume expansion data after linear thermal effects, deduced from low $T$ thermal behavior, are subtracted (b). In both compounds, an extra $0.5-1 \%$ volume expansion cannot be accounted for by the regular thermal expansion observed at low temperature. Our proposition is that this additional expansion originates from the rotation of anti-tetrahedral units, at the origin of the high mobility of $\mathrm{O} 2 / \mathrm{O} 3$ oxide ions in the anti-framework tunnels. Such an interpretation is illustrated in Figure 10, which combines the experimental data of Figure 1 and our model calculation of Figure 7. A rotation of the order of $1^{\circ}$, over about $500 \mathrm{~K}$, of $\left[\mathrm{O} 1(\mathrm{La}, \mathrm{Sr})_{3} \mathrm{Mo}\right]$ units around their 3 -fold axis would account for the observed extra increase in cell volume.

In the next section, we will try to evidence a correlation between such a volume expansion through anti-tetrahedra

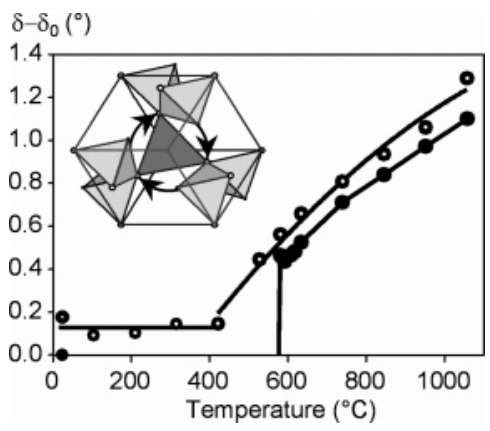

Figure 10. Thermal expansion data of Figure 9 replotted as a function of the $\delta$ rotation angle (in insert) deduced from analytical formula (5), for $\mathrm{La}_{2} \mathrm{Mo}_{2} \mathrm{O}_{9}$ (black circles) and $\mathrm{La}_{1.9} \mathrm{Sr}_{0.1} \mathrm{Mo}_{2} \mathrm{O}_{8.95}$ (open circles).

Table 1. Potential Parameter Set Used for Molecular Dynamics Simulations

\begin{tabular}{ccccc}
\hline & \multicolumn{3}{c}{ parameters } \\
\cline { 2 - 5 } ion & \multicolumn{1}{c}{$\mathrm{Z}_{\mathrm{i}}$} & $a_{i}(\AA)$ & $b_{i}(\AA)$ & $c_{i}\left(\left(\mathrm{~J} \AA^{6} \mathrm{~mol}^{-1}\right)^{1 / 2}\right)$ \\
\hline $\mathrm{Mo}^{6+}$ & $4.05^{a}$ & 0.887 & 0.0428 & 0.00 \\
$\mathrm{La}^{3+}$ & $2.025^{a}$ & 1.410 & 0.0540 & 0.00 \\
$\mathrm{O}^{2-}$ & $-1.35^{a}$ & $1.847^{a}$ & $0.166^{a}$ & $1294^{a}$
\end{tabular}

${ }^{a}$ Taken from ref 26 .

rotation and an increase of oxide-ion conduction, using molecular dynamics simulations.

\section{Molecular Dynamics Simulations}

To check the incidence of such a tilt/rotation of antitetrahedra units on the migration of $\mathrm{O} 2$ and $\mathrm{O} 3$ oxygen sites located in the tunnels of the anti-structure, a series of molecular dynamics simulations were carried out with different rotation angles of these units. The pair-potential function used in this study is given in the Experimental Section. The simulation parameters for $\mathrm{O}^{2-}$ ions and effective charge for all ions were taken from ref 26 . The parameters for $\mathrm{Mo}^{6+}$ and $\mathrm{La}^{3+}$ ions were determined so as to minimize atomic displacement from the atomic positions determined on a $\mathrm{La}_{2} \mathrm{MoO}_{6}$ crystal. ${ }^{27}$ This set of parameters, as listed in Table 1, has been shown to reproduce accurately the first coordination sphere of $\mathrm{La}$ and $\mathrm{Mo}$ in $\mathrm{La}_{2} \mathrm{Mo}_{3} \mathrm{O}_{12},{ }^{28} \mathrm{La}_{2}-$ $\mathrm{Mo}_{4} \mathrm{O}_{15},{ }^{29}$ and $\beta-\mathrm{La}_{2} \mathrm{Mo}_{2} \mathrm{O}_{9}$ at $943 \mathrm{~K} .{ }^{18}$ The pair radial distribution functions, involving $\mathrm{O} 2$ and $\mathrm{O} 3$ oxide ions only, in a 64 cells sample of $\beta-\mathrm{La}_{2} \mathrm{Mo}_{2} \mathrm{O}_{9}$ after relaxation at 943 $\mathrm{K}$ (see below) are shown in Figure 11 (for full coordination sphere of cations, add one $\mathrm{O} 1$ for $\mathrm{Mo}^{6+}$ and three $\mathrm{O} 1$ for $\left.\mathrm{La}^{3+}\right)$. They are consistent with the crystal structure. ${ }^{18}$

A cubic MD simulation box consisting of $4 \mathrm{a} \times 4 \mathrm{a} \times 4 \mathrm{a}$ crystallographic unit cells was chosen. The $d_{\mathrm{ll}}, d_{\mathrm{lm}}$, and $d_{\mathrm{mo}}$ interatomic distances of $\beta-\mathrm{La}_{2} \mathrm{Mo}_{2} \mathrm{O}_{9}$ at $943 \mathrm{~K}$ were taken as reference. ${ }^{18} \mathrm{~A}$ series of rotation angles were chosen, spanned around the value measured in $\beta-\mathrm{La}_{2} \mathrm{Mo}_{2} \mathrm{O}_{9}$ at this temperature $\left(\delta=-5.85^{\circ}\right)$. The corresponding crystal cell parameters $a$ and $\mathrm{La}, \mathrm{Mo}$, and $\mathrm{O}_{1}$ atomic coordinates, as

(26) Hayashi, H.; Watanabe, M.; Ohuchida, M.; Inaba, H.; Hiei, Y.; Yamamoto, T.; Mori, M. Solid State Ionics 2001, 144, 301-313.

(27) Efremov, V. A.; Tyulin, A. V.; Trunov V. K. Koord. Khim. 1987, 13, 1276-1282 (in Russian) - ICSD data 79807.

(28) Jeitschko, W. Acta Crystallogr. B 1973, 29, 2074-2081.

(29) Dubois, F.; Goutenoire, F.; Laligant, Y.; Suard E.; Lacorre, P. J. Solid State Chem. 2001, 159, 228-233. 

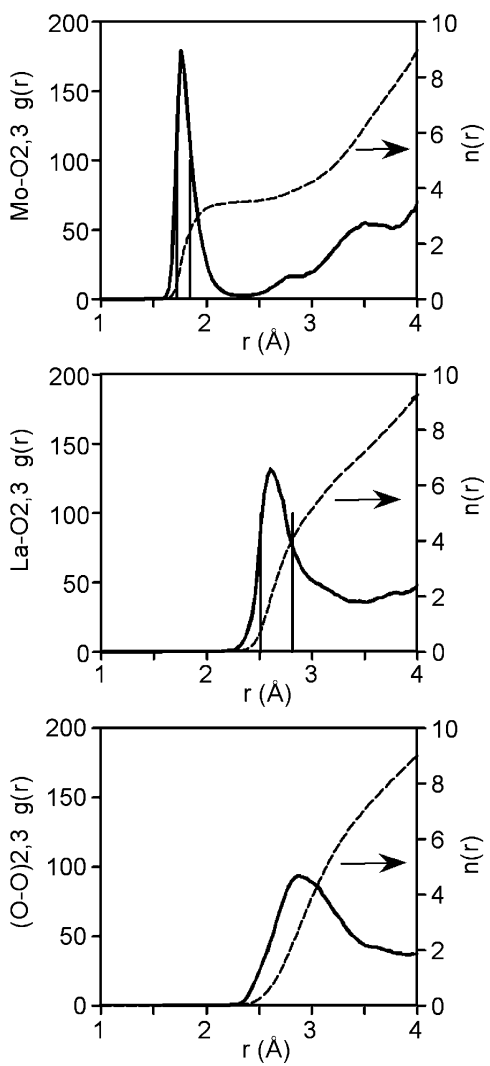

Figure 11. Radial distribution function $g_{i j}(r)$ and coordination number distribution $n_{i j}(r)$ versus the interionic distance $r$ in the cation-anion (Mo-O2,3 and $\mathrm{La}-\mathrm{O} 2,3)$ and anion-anion $(\mathrm{O} 2,3-\mathrm{O} 2,3)$ pairs, after molecular dynamics relaxation at $943 \mathrm{~K}$. For full cationic coordination numbers, one and three $\mathrm{O} 1$ extra neighbors should be added to Mo and La polyhedra, respectively. Vertical lines correspond to the crystal structure interatomic distances (from ref 18)

Table 2. Crystallographic Cell Parameter $a$ and Corresponding Atom

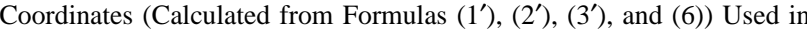
the Molecular Dynamics Simulations

\begin{tabular}{cclll}
\hline$\delta(\mathrm{deg})$ & $a(\AA)$ & \multicolumn{1}{c}{$x(\mathrm{La})$} & \multicolumn{1}{c}{$x(\mathrm{Mo})$} & \multicolumn{1}{c}{$x\left(\mathrm{O}_{1}\right)$} \\
\hline 0 & 7.273352 & 0.875000 & 0.163496 & 0.309474 \\
-5 & 7.245674 & 0.856058 & 0.169002 & 0.315537 \\
-5.85 & $7.23511^{a}$ & $0.8528^{a}$ & $0.1697^{a}$ & $0.3165^{a}$ \\
-7.5 & 7.211127 & 0.846496 & 0.171172 & 0.318409 \\
-10 & 7.162853 & 0.836824 & 0.172958 & 0.321188 \\
-15 & 7.025518 & 0.816987 & 0.175372 & 0.326500 \\
-20 & 6.834715 & 0.796198 & 0.176189 & 0.331536
\end{tabular}

${ }^{a}$ From ref 18.

deduced from formulas $(6),\left(1^{\prime}\right),\left(2^{\prime}\right)$, and $\left(3^{\prime}\right)$, respectively, were kept fixed during each simulation run (see Table 2). The $\mathrm{O} 2$ and $\mathrm{O} 3$ oxygen ions where chosen randomly to match the occupation ratio, but a constraint was used to exclude small $\mathrm{O}-\mathrm{O}$ distances. However, short $\mathrm{O}-\mathrm{O}$ (i.e., 1.2-1.7 $\AA$ ) could not be avoided. The box thus contained $256 \mathrm{Mo}, 256 \mathrm{La}, 256 \mathrm{O} 1,600 \mathrm{O} 2$, and $296 \mathrm{O} 3$ ions, periodic boundary conditions were employed, and the time step was equal to $2 \times 10^{-15} \mathrm{~s}$. The initial velocity of $\mathrm{O} 2$ and $\mathrm{O} 3$ ions were sampled from a Maxwell-Boltzmann distribution at the temperature specified for the simulation, with Mo, La, and $\mathrm{O} 1$ being kept fixed. The system was relaxed at $943 \mathrm{~K}$ for 25000 time steps and then heated at $1500 \mathrm{~K}$ in one step and then relaxed again for 80000 more time steps. The 1500 $\mathrm{K}$ temperature was selected instead of $943 \mathrm{~K}$ in order to obtain accurate displacement.

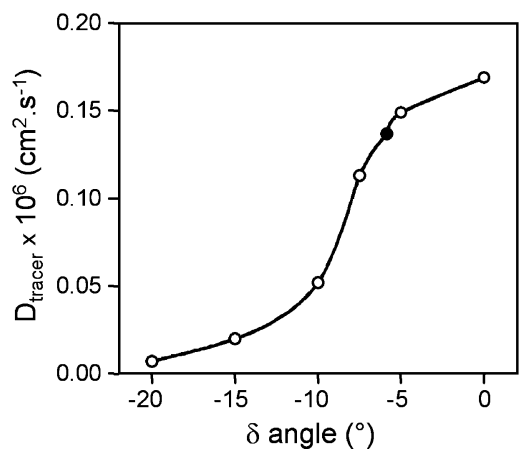

Figure 12. $\mathrm{O} 2+\mathrm{O} 3$ diffusion coefficient at various anti-tetrahedra rotation angles $\delta$, from molecular dynamics simulations at $1500 \mathrm{~K}$. The reported values correspond to the average over 10 runs of 160 ps duration each. The solid dot corresponds to the structural framework arrangement of $\beta$ - $\mathrm{La}_{2}$ $\mathrm{Mo}_{2} \mathrm{O}_{9}$ at $943 \mathrm{~K}^{18}$

The bulk oxygen tracer diffusion coefficient $D_{\text {tracer }}$ was computed via the time-dependent mean square displacement ${ }^{30}$ denoted by $s^{2}(t)$ :

$$
s^{2}(t)=\frac{1}{N} \sum_{1}^{N}\left\langle\left[\vec{r}_{n}\left(t_{\mathrm{o}}+t\right)-\vec{r}_{n}\left(t_{\mathrm{o}}\right)\right]^{2}\right\rangle=C+6 D(t) \times t
$$

where $\vec{r}_{\mathrm{n}}(t)$ is the position vector of the $n$th oxygen ion (O2 or O3) at the time $t ; C$ is a constant. $D_{\text {tracer }}$ is taken as the asymptotic value of $D(t)$ with a time calculation of $160 \mathrm{ps}$ (i.e., 80000 time steps).

The dependence of the diffusion coefficient on the antitetrahedra tilt/rotation angle is plotted in Figure 12. A significant increase, of about 1 order of magnitude in a few degrees of rotation, is observed between $-10^{\circ}$ and $-5^{\circ}$, that is to say just below the tilting angle measured at $670{ }^{\circ} \mathrm{C}$ in $\beta-\mathrm{La}_{2} \mathrm{Mo}_{2} \mathrm{O}_{9}\left(\delta=-5.85^{\circ}\right)$. These simulations therefore show that an opening up of the anti-structure tunnels through antitetrahedra rotation would be responsible for an increase in the $\mathrm{O} 2$ and $\mathrm{O} 3$ oxygen mobility, thus confirming the selfconsistency of our model.

We also attempted to observe individual oxygen jumps during the simulation. Since trajectory analysis requires long displacements, we had to use a smaller box, i.e., a $3 \mathrm{a} \times 3 \mathrm{a}$ $\times$ 3a crystallographic unit cell (108 Mo, $108 \mathrm{La}, 108$ O1, $253 \mathrm{O} 2$, and $125 \mathrm{O} 3$ ions) in order to reduce time calculations. Figure 13 shows 3D plots of the trajectory of some $\mathrm{O} 2$ or $\mathrm{O} 3$ oxygen recorded at $1500 \mathrm{~K}$ in the most favorable geometry $\left(\delta=0^{\circ}\right)$, as well as the related atomic coordinates as a function of time. One clearly sees discrete jumps, which could be responsible for the oxygen diffusion in $\mathrm{La}_{2} \mathrm{Mo}_{2} \mathrm{O}_{9}$. The mean jump length involving $\mathrm{O} 2 / \mathrm{O} 3$ ions is $2.8 \AA$, close to the mean $\mathrm{O}-\mathrm{O}$ distance obtained on the simulated radial distribution function, and to the nearest oxide ion neighbors distance measured from the short-range-order modulation of the neutron diffraction background. ${ }^{31,16}$ Note also that the jumps detected on $\mathrm{O} 2$ and $\mathrm{O} 3$ oxide ions \#699 and \#402 are time-correlated at around $330 \mathrm{ps}$, with ion $\mathrm{O} 2$ occupying after its jump the previous position of ion $\mathrm{O} 3$ just before its jump.

(30) Sangster, M. J. L.; Dixon, M. Adv. Phys. 1976, 25, 247-342.

(31) Goutenoire, F.; Isnard, O.; Retoux, R.; Lacorre P. Chem. Mater. 2000, $12,2575-2580$ 

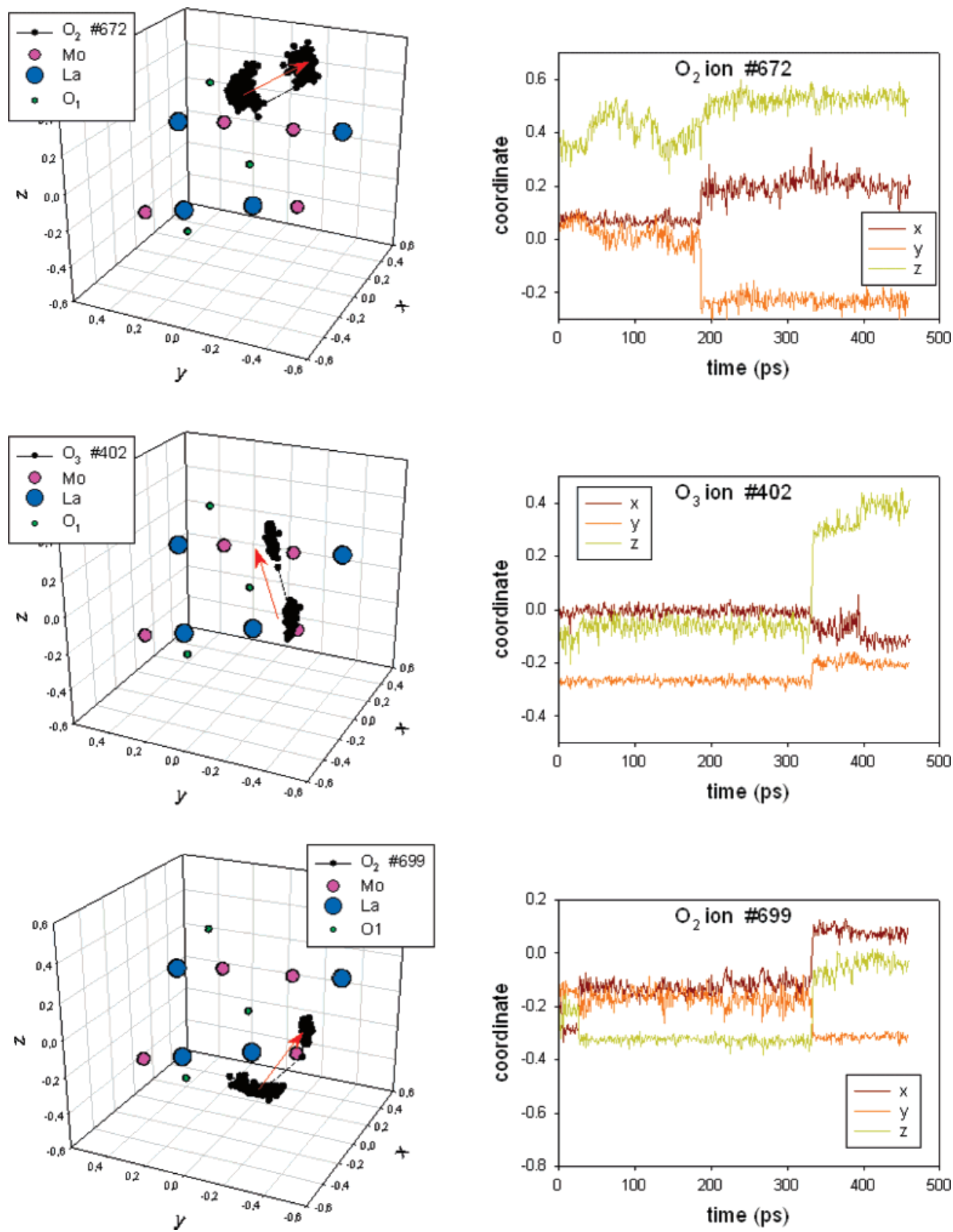

Figure 13. From the molecular dynamics simulation of a sample with fully opened framework $\left(\delta=0^{\circ}\right)$ at $1500 \mathrm{~K}$, the trajectory and atomic coordinates versus time of some oxide ions indexed as \#402 (O3), \#672 (O2), and \#699 (O3). NB: O2 and O3 are labeled according to their original positioning, but subsequent migrations prevent any real differentiated allocation (localizations in black in the 3D trajectory charts).

\section{Discussion}

The flexibility of polyhedral networks, and in particular tetrahedral networks, has been extensively studied by various techniques, including simulation and geometrical analysis (see for instance refs 32 and references therein). The basic concept of all these studies is that of the "rigid-unit mode" (abbreviated as RUM) ${ }^{33}$ model, which assumes that there exist, in these networks, rigid polyhedral units whose low-

(32) (a) Wells, S. A.; Dove, M. T.; Tucker, M. G. J. Phys.: Condens. Matter 2002, 14, 4567-4584. (b) Khosrovani, N.; Sleight, A. W. J. Solid State Chem. 1996, 121, 2-11. (c) Tao, J. Z.; Sleight, A. W. J. Solid State Chem. 2003, 173, 442-448. (d) Heine, V.; Welche, P. R. L. J. Am. Ceram. Soc. 1999, 82, 1793-802. (e) Gambhir M.; Dove, M. T.; Heine, V. Phys. Chem. Miner. 1999, 26, 484-495. energy vibration modes ensure structural flexibility. The most famous and studied applications of such a concept concern silicates or alumino-silicates(phosphates) with corner-sharing rigid $(\mathrm{Si}, \mathrm{Al}, \mathrm{P}) \mathrm{O}_{4}$ tetrahedra. As a matter of fact, in $\mathrm{SiO}_{4 / 2}$ networks, the energy cost for a distortion of the 2-fold coordination environment of oxide ions is probably smaller than that for a distortion of the 4-fold coordination polyhedra of silicon.

Our approach in this paper is to invert the pattern and use $\mathrm{OM}_{4}$ anti-tetrahedral units as the building rigid blocks of the RUM model. This is a risky assumption since the

(33) (a) Dove, M. T.; Giddy, A. P.; Heine, V. Trans. Am. Crystallogr. Assoc. 1993, 27, 65-74. (b) Dove, M. T.; Heine, V.; Hammonds, K. D. Miner. Magn. 1995, 59, 629-639. 
coordination sphere of cations is usually larger, in term of ligand numbers, than the coordination sphere of anions, so that a distortion of the latter would remain less energy costly than a distortion of the former, as in the previous silicate cases. Indeed, if one takes into account partial occupancies of oxide ions, the average coordination numbers of $\mathrm{Mo}^{6+}$ and $\mathrm{La}^{3+}$ in $\beta$ - $\mathrm{La}_{2} \mathrm{Mo}_{2} \mathrm{O}_{9}$ are 4.5 and 10 , respectively, ${ }^{18}$ as compared to 4 for $\mathrm{O} 1$ anion. However, as mentioned earlier and due to the fast oxide-ion properties of this molybdate, $\mathrm{O} 2$ and $\mathrm{O} 3$ are rather mobile ligands around molybdenum and lanthanum, themselves elements which tolerate a high flexibility in their coordination spheres. If one assumes that fully occupied $\mathrm{O} 1$ is the most tightly bound ligand, therefore creating the most rigid links, $\mathrm{Mo}^{6+}$ and $\mathrm{La}^{3+}$ have only one and three such rigid bounds in their surroundings, respectively, ${ }^{18}$ whereas $\mathrm{O} 1$ has four. And on average, one therefore ends up with twice more strong bounds around O1 than around cations, a reversed situation when compared to that of silicates.

Even if at first sight it might appear astonishing that the flexibility of the $\beta$ - $\mathrm{La}_{2} \mathrm{Mo}_{2} \mathrm{O}_{9}$ framework could rely upon the displacement of such heavy atoms as La or Mo, a similar case has already been referred to in the literature. In zirconium tungstate $\mathrm{ZrW}_{2} \mathrm{O}_{8}$, a compound known for its negative thermal expansion properties, it has been shown that the $\mathrm{Zr}-\mathrm{O}-\mathrm{W}$ linkage remains rather stiff with temperature (with no important static ${ }^{34}$ or dynamic ${ }^{35}$ opening up of the interatomic angle) and that the low-energy vibrational modes involve heavy $\mathrm{Zr}$ and $\mathrm{W}$ atoms. That a comparable type of low-energy mode involving rigid $\mathrm{La}-\mathrm{O}-(\mathrm{Mo}, \mathrm{B})$ links could occur in $\mathrm{La}_{2}(\mathrm{Mo}, \mathrm{B})_{2} \mathrm{O}_{9}$ is therefore not so surprising.

On the other hand, even with a certain stiffness of $\mathrm{La}-\mathrm{O} 1-(\mathrm{Mo}, \mathrm{B})$ links in anti-tetrahedral units, the assumption that these units keep exactly the same geometry upon heating, even with some isotropic thermal expansion, might not be very realistic. As a matter of fact, we have already shown that anti-tetrahedra can distort upon chemical substitution, ${ }^{3}$ and it would not be so surprising if chemical bonds had different thermal expansion depending on the nature of the involved cation. Such additional effect, not taken into account in our model, could for instance be at the origin of differences in oxygen tracer diffusion coefficients, which appear to be somewhat smaller in our MD simulations than the ones measured on real samples. ${ }^{21}$ Nevertheless, we think that our proposition, even crude as it is, gives a plausible explanation for the main structural/transport anomalies observed in these compounds and should be tested further.

(34) Mary, T. A.; Evans, J. S. O.; Vogt, T.; Sleight, A. W. Science 1996, 272, 90-92.

(35) Cao, D.; Bridges, F.; Kowach, G. R.; Ramirez A. P. Phys. Rev. B 2003, 68, 014303 .
It is also probable that the observed lattice expansion does not result from a smooth regular opening of the anti-structural framework only, but that it takes place through a libration process with dynamical breathing of the framework. Such a libration would thus assist oxygen migration, in somewhat the same way as in LLTO perovskites, octahedral librations (which allow for the opening/closing of the inter-cage bottleneck), do for lithium migration.

\section{Conclusion}

In this paper, we have studied through a mathematical analysis the ability of the $\beta-\mathrm{La}_{2} \mathrm{Mo}_{2} \mathrm{O}_{9}$ cationic sublattice to distort as a semirigid framework of tilting [OLa $3 \mathrm{Mo}]$ antitetrahedral units. It is theoretically possible in a surprisingly large rotational domain (although atomic repulsion certainly limits it within a narrower range). It has been proposed that the extra volume expansion, observed at the postulated Arrhenius/VTF transition, originates from such a tilting mechanism. This hypothesis has been tested using molecular dynamics simulations, which confirmed that such an opening of anti-tetrahedral framework induces an increase of oxideion diffusion in the tunnels of the structure. However, the magnitude of the structural distortion is expected to be very small (around $1^{\circ}$ over a $500 \mathrm{~K}$ range ${ }^{36}$ ), which should make it difficult to be detected, specially as it is most certainly correlated to a dynamic redistribution of $\mathrm{O} 2 / \mathrm{O} 3$ ion sites. Further studies using different techniques will be devoted to its detection.

Finally, the current study has shown that the way we are looking at structures and describing them is not neutral since it has an incidence on our understanding of their properties. As a matter of fact, this analysis would not have been possible if an alternative description of the structural arrangement of $\beta$ - $\mathrm{La}_{2} \mathrm{Mo}_{2} \mathrm{O}_{9}$ had not been striven for, inspired by the pioneering work by O'Keeffe and Hyde 20 years ago. $^{24}$

Acknowledgment. B. Boulard is grateful to J. Kieffer and C.A. Angell (Arizona State University) for providing the Molecular Dynamics program.

(36) Although comparable in magnitude, the first-order transition in $\mathrm{La}_{2}$ $\mathrm{Mo}_{2} \mathrm{O}_{9}$ cannot be explained the same way since it results from an order-disorder type transition between phases with different symmetries. ${ }^{18,37}$ The physical origin of the transition is however comparable to that observed in cubic LAMOX compounds, except that in this last case the random cationic distribution prevents any oxide-ion/vacancy ordering (and therefore any symmetry breaking).

(37) Radosavljevic Evans, I.; Howard, J. A. K.; Evans, J. S. O. Chem. Mater. 2005, 17, 4074-4077 